\title{
Association of duration of residence in the southeastern United States with chronic kidney disease may differ by race: the REasons for Geographic and Racial Differences in Stroke (REGARDS) cohort study
}

Laura Plantinga ${ }^{1,2^{*}}$, Virginia J Howard ${ }^{3}$, Suzanne Judd ${ }^{4}$, Paul Muntner ${ }^{3}$, Rikki Tanner ${ }^{3}$, Dana Rizk ${ }^{5}$, Daniel T Lackland ${ }^{6}$, David G Warnock ${ }^{5}$, George Howard ${ }^{4}$ and William M McClellan ${ }^{1,7}$

\begin{abstract}
Background: Prior evidence suggests that longer duration of residence in the southeastern United States is associated with higher prevalence of diabetes and hypertension. We postulated that a similar association would exist for chronic kidney disease (CKD).

Methods: In a national population-based cohort study that enrolled 30,239 men and women $\geq 45$ years old (42\% black/58\% white; 56\% residing in the Southeast) between 2003 and 2007, lifetime southeastern residence duration was calculated and categorized [none (0\%), less than half $(>0-<50 \%)$, half or more $(\geq 50-<100 \%)$, and all (100\%)]. Prevalent albuminuria (single spot urinary albumin:creatinine ratio of $\geq 30 \mathrm{mg} / \mathrm{g}$ ) and reduced kidney function (estimated glomerular filtration rate $<60 \mathrm{ml} / \mathrm{min} / 1.73 \mathrm{~m}^{2}$ ) were defined at enrollment. Incident end-stage renal disease (ESRD) during follow-up was identified through linkage to United States Renal Data System.

Results: White and black participants most often reported living their entire lives outside (35.7\% and 27.0\%, respectively) or inside (27.9\% and 33.8\%, respectively) the southeastern United States. The prevalence of neither albuminuria nor reduced kidney function was statistically significantly associated with southeastern residence duration, in either race. ESRD incidence was not statistically significantly associated with all vs. none southeastern residence duration ( $\mathrm{HR}=0.50,95 \% \mathrm{Cl}, 0.22-1.14)$ among whites, whereas blacks with all vs. none exposure showed increased risk of ESRD ( $H R=1.63,95 \% \mathrm{Cl}, 1.02-2.63$; Pracexduration $=0.011)$.
\end{abstract}

Conclusions: These data suggest that blacks but not whites who lived in the Southeast their entire lives were at increased risk of ESRD, but we found no clear geographic pattern for earlier-stage CKD.

Keywords: Albuminuria, Kidney function, End-stage renal disease, Stroke belt, African-American, Geographic variation

\footnotetext{
* Correspondence: laura.plantinga@emory.edu

'Department of Epidemiology, Rollins School of Public Health, Emory

University School of Medicine, Emory University, Atlanta, GA, USA

${ }^{2}$ Laney Graduate School, Emory University School of Medicine, Emory

University, Atlanta, GA, USA

Full list of author information is available at the end of the article
} 


\section{Introduction}

Chronic kidney disease (CKD), defined by albuminuria or reduced estimated glomerular filtration rate (eGFR), is common among adults in the United States (estimated prevalence $>10 \%$ ) [1], and, in 2009, more than 600,000 individuals with CKD were treated for end-stage renal disease (ESRD) [2], requiring dialysis or kidney transplantation to sustain life. Substantial geographic variation exists in the age-, race- and sex-adjusted incidence of ESRD in the United States, and many of the southeastern states (which overlay the so-called "stroke belt" [3]) have higher incidence than many other U.S. regions [2]. Further, both diabetes [4] and hypertension [5], which are strong risk factors for CKD, have been shown to be more prevalent in the southeastern United States, compared to the rest of the country. This raises the possibility that regional factors that are associated with increased risk of developing diabetes and hypertension during one's lifetime, as well as the diseases themselves, might contribute to a higher risk of CKD and ESRD among residents of this region. Factors that could vary by region and also affect these risks include behavioral (e.g., diet and physical activity), environmental (e.g., water quality and food availability), and possibly unknown populationlevel genetic factors.

Despite increasing interest in the geographic aspects of CKD epidemiology [6], there remains little known about the associations of the duration of residence in the southeastern United States with prevalence of CKD and incidence of ESRD. Additionally, since diabetes and hypertension have also been shown to be more prevalent among blacks compared to whites [7], the degree to which race may affect such associations is of interest. Thus, we hypothesized that, in a national populationbased cohort of community-dwelling individuals aged $\geq 45$ years [the REasons for Geographic and Racial Differences in Stroke (REGARDS) cohort], longer duration of residence in the Southeast would be associated with higher prevalence of albuminuria and reduced kidney function and incidence of ESRD in both blacks and whites.

\section{Results}

\section{Participant characteristics}

Participants with complete residence information had a mean age of 65 years; overall, approximately $56 \%$ were female, $40 \%$ were black, and $35 \%$ were college graduates. In general, females, those without a college education, currently living in a non-urban location, with diabetes, and with hypertension had higher southeastern residence duration. Participant characteristics by southeastern residence duration and race are shown in Table 1. Black participants were more likely to be younger and female and to have less education, lower income, lower residential mobility, urban residence, higher BMI, diabetes and hypertension, compared to whites; they were less likely to use NSAIDs regularly. On average, blacks had higher albumin:creatinine ratios and eGFRs than whites.

The majority of participants had spent their entire lifetime either outside (32.3\%) or inside (30.3\%) the Southeast. The median southeastern residence duration was $46.8 \%$ (47.8\% for whites and $45.8 \%$ for blacks; $33.9 \%$ for males and $59.4 \%$ for females). Figure 1 shows that the majority of participants spent $100 \%$ of their lives ("all") or $0 \%$ of their lives ("none") in the Southeast. White participants more often, and black participants less often, reported no vs. entire life in the Southeast (whites, $35.7 \%$ vs. $27.9 \%$; blacks, $27.0 \%$ vs. $33.8 \%$ ).

\section{Prevalence of albuminuria by southeastern residence duration}

Albuminuria was more prevalent in both whites and blacks who either spent none or all of their life in the Southeast, relative to those who spent part but not all of their life in the region (Table 2). Additionally, the crude prevalence of albuminuria was higher in blacks than whites in every southeastern residence duration category. The PORs, relative to the "none" $(0 \%)$ southeastern residence duration category, show somewhat increased prevalence for the "all" (100\%) southeastern residence duration category. For example, with adjustment for age and sex and compared to no southeastern residence, whites who spent all of their lives in the Southeast had a POR of 1.16 (95\% CI, 1.02-1.31). However, this association became non-significant with further adjustment for clinical factors and SES (Table 3). In the black population, we found no pattern of higher prevalence with longer duration of southeastern residence. Rather, blacks with lifetime southeastern residence duration less than half $(>0 \%$ and $<50 \%)$ and half or more $(\geq 50 \%$ and $<100 \%)$ had age- and sex-adjusted PORs of 0.87 (95\% CI, 0.76-1.00) and 0.80 (95\% CI, 0.68-0.95), respectively, relative to blacks with no residence in the region, and these associations persisted with further adjustment. The statistical significance of the interaction by race of the association between southeastern exposure and albuminuria prevalence was attenuated with adjustment for SES.

In sensitivity analyses, income-stratified analyses (Table 4) showed that the lack of association of albuminuria with southeastern residence duration was similarly present in high $(>\$ 35,000)$ - and low $(<\$ 35,000)$-income groups. Neither the three-way interaction term of income, race, and southeastern residence duration nor two-way interactions of race with southeastern residence duration in stratified models were statistically significant. When residence duration was categorized in evenly spaced intervals of length $20 \%$ (excluding the $0 \%$ 
Table 1 Cohort participant characteristics, by race and southeastern residence duration categories

\begin{tabular}{|c|c|c|c|c|c|c|c|c|c|c|}
\hline \multirow{2}{*}{$\begin{array}{l}\text { Southeastern residence } \\
\text { duration: }\end{array}$} & \multicolumn{5}{|c|}{ White } & \multicolumn{5}{|c|}{ Black } \\
\hline & Total & None & $<$ Half & $\geq$ Half & All & Total & None & $<$ Half & $\geq$ Half & All \\
\hline$N(\%)$ & 16,381 & $5,851(35.7)$ & 2,447 (14.9) & $3,509(21.4)$ & $4,574(27.5)$ & 10,689 & $2,885(27.0)$ & $2,566(24.0)$ & $1,626(15.2)$ & $3,612(33.8)$ \\
\hline \multicolumn{11}{|l|}{ Demographic } \\
\hline Mean age in years (SD) & $65.5(9.5)$ & $65.9(9.7)$ & $65.5(9.1)$ & $65.4(9.1)$ & $65.1(9.5)$ & $64.1(9.2)$ & $64.4(9.4)$ & $66.1(8.8)$ & $62.5(8.7)$ & $63.0(9.2)$ \\
\hline$\%$ female & 50.5 & 47.4 & 44.1 & 52.0 & 56.6 & 63.9 & 63.3 & 59.4 & 61.6 & 68.7 \\
\hline \multicolumn{11}{|l|}{ Socioeconomic status } \\
\hline$\%$ college graduate & 41.4 & 45.8 & 50.7 & 42.7 & 29.6 & 26.2 & 28.8 & 24.4 & 30.1 & 23.7 \\
\hline \multicolumn{11}{|l|}{ Annual income } \\
\hline$\%<\$ 35,000$ & 34.4 & 32.3 & 29.3 & 35.0 & 39.6 & 52.8 & 49.4 & 51.7 & 51.8 & 57.0 \\
\hline$\% \geq \$ 35,000$ & 53.4 & 55.6 & 59.8 & 53.7 & 47.0 & 34.7 & 38.9 & 36.6 & 37.6 & 28.8 \\
\hline$\%$ refused & 12.1 & 12.1 & 11.0 & 11.3 & 13.3 & 12.4 & 11.8 & 11.8 & 10.7 & 14.2 \\
\hline \multicolumn{11}{|l|}{ Residence } \\
\hline$\% 5+$ lifetime moves ${ }^{a}$ & 50.2 & 46.9 & 74.9 & 69.7 & 26.2 & 17.6 & 14.7 & 21.4 & 37.6 & 8.2 \\
\hline$\% \geq 20$ years at current residence & 53.8 & 54.0 & 33.7 & 61.1 & 58.6 & 64.9 & 62.9 & 68.7 & 70.3 & 61.5 \\
\hline$\%$ urban & 69.3 & 81.8 & 67.1 & 65.9 & 56.4 & 90.4 & 99.0 & 96.0 & 82.4 & 83.1 \\
\hline \multicolumn{11}{|l|}{ Access } \\
\hline$\%$ insured & 95.8 & 96.5 & 95.9 & 95.7 & 94.8 & 90.3 & 92.2 & 93.2 & 89.1 & 87.3 \\
\hline$\%$ with regular medical care & 84.3 & 84.4 & 83.1 & 84.4 & 84.6 & 81.7 & 80.9 & 81.4 & 82.5 & 82.3 \\
\hline \multicolumn{11}{|l|}{ Clinical } \\
\hline$\%$ current smoker & 12.3 & 10.9 & 11.8 & 13.8 & 13.2 & 17.2 & 18.3 & 16.9 & 19.4 & 15.6 \\
\hline$\%$ obese $\left(\mathrm{BMI}>30 \mathrm{~kg} / \mathrm{m}^{2}\right)$ & 30.9 & 30.4 & 30.5 & 29.2 & 33.2 & 48.7 & 46.9 & 46.3 & 47.2 & 52.4 \\
\hline$\%$ using NSAIDS & 16.3 & 15.6 & 15.2 & 17.8 & 16.7 & 11.9 & 11.7 & 11.2 & 12.2 & 12.3 \\
\hline$\%$ using ACEI/ARBs & 31.6 & 29.0 & 30.8 & 32.8 & 34.4 & 42.0 & 39.4 & 40.6 & 41.1 & 45.3 \\
\hline$\%$ with diabetes & 15.3 & 13.2 & 14.3 & 16.2 & 18.0 & 30.3 & 28.1 & 27.4 & 29.9 & 34.3 \\
\hline$\%$ with hypertension & 50.3 & 47.3 & 49.7 & 51.3 & 53.7 & 71.7 & 69.0 & 72.3 & 69.6 & 74.3 \\
\hline$\%$ family history of ESRD & 4.7 & 4.3 & 4.1 & 4.8 & 5.6 & 10.7 & 8.8 & 9.5 & 11.2 & 12.7 \\
\hline Mean $A^{2} R^{b}(S D)$ & $9.30(2.94)$ & $9.21(2.92)$ & $8.76(2.77)$ & $9.39(3.06)$ & $9.68(3.06)$ & $11.94(4.06)$ & $12.18(4.06)$ & $11.70(4.06)$ & $10.59(3.82)$ & $12.55(4.18)$ \\
\hline Mean eGFR (SD) & 82.6 (17.1) & $82.1(17.0)$ & $83.2(16.4)$ & $82.8(17.1)$ & $82.8(17.5)$ & $88.7(23.3)$ & $88.9(23.5)$ & $86.5(22.8)$ & $90.4(21.8)$ & $89.4(24.1)$ \\
\hline
\end{tabular}

Southeastern residence duration: total, all participants; none, $0 \%$ of life spent in Southeast; $<$ half, $>0 \%-50 \%$ of life spent in Southeast; $>$ half, $>50 \%-<100 \%$ of life spent in Southeast; all, $100 \%$ of life spent in Southeast. The Southeast included North Carolina, South Carolina, Georgia, Alabama, Mississippi, Tennessee, Arkansas, and Louisiana; other included the 40 other contiguous U.S. states (excluding Alaska and Hawaii).

BMI, body mass index $\left(\mathrm{kg} / \mathrm{m}^{2}\right.$ ); ACEI, angiotensin-converting enzyme inhibitor; ARB, angiotensin receptor blocker; NSAID, non-steroidal anti-inflammatory drug; ACR, albumin:creatinine ratio ( $\left.\mathrm{mg} / \mathrm{g}\right)$; eGFR; estimated glomerular filtration rate $\left(\mathrm{ml} / \mathrm{min} / 1.73 \mathrm{~m}^{2}\right)$. Diabetes and hypertension were defined by self-reported diagnoses; self-reported use of insulin or oral hypoglycemic and anti-hypertensive medications; or measured fasting blood glucose $>126 \mathrm{mg} / \mathrm{dl}$ or random glucose $\geq 200 \mathrm{mg} / \mathrm{dl}$ and blood pressure $>140 />90 \mathrm{mmHg}$, respectively. blood glucose $\geq 126 \mathrm{mg} / \mathrm{dl}$ or random glucose $\geq 200 \mathrm{mg} / \mathrm{dl}$ and blood pressure $>140 />90 \mathrm{mmHg}$, respectively.

Missing data (whites and blacks): education, $n=19$; insurance; $n=21$; routine source of medical care, $n=970$; urbanization of current residence, $n=2,612$; smoking, $n=105 ; \mathrm{BMI}, n=187$; regular use of NSAIDs, $n=101$; diabetes, $n=969$; hypertension, $n=65$, albuminuria, $n=1273$, eGFR, $n=1105$. For those variables with $>10 \%$ of data missing, 'unknown' was included as a category in the table.

$P<0.001$ in whites and blacks across southeastern exposure categories, by chi-square (categorical) and ANOVA (continuous) tests, for all characteristics shown, except routine site for medical care ( $P>0.05$ for whites and blacks).

aLifetime moves comprise moves to the Southeast, to the rest of the United States, and outside of the United States, regardless of duration.

${ }^{\mathrm{b}}$ Geometric mean. 
and $100 \%$ categories), results were similar: having a southeastern residence duration of $80-99 \%$ was associated with a fully adjusted POR of 0.71 (95\% CI, 0.580.88 ), relative to $0 \%$ among blacks, but no other residence duration category was associated with prevalent albuminuria in blacks; no associations were seen among whites. Additionally, whether participants had spent the first 18 years of life in the Southeast (vs. not) was not associated with albuminuria: fully adjusted $\mathrm{POR}=1.02$ (95\% CI, 0.94-1.13) and 0.94 (95\% CI, 0.84-1.05), for whites and blacks, respectively. Finally, the age $\times$ duration term was not statistically significant for whites $(P=0.99)$ or blacks $(P=0.42)$ in fully adjusted models.

\section{Prevalence of reduced kidney function by southeastern residence duration}

Crude prevalence of reduced kidney function was similar across all southeastern residence duration categories, regardless of race (Table 2). For most categories, blacks had higher prevalence of reduced kidney function than whites (Table 2). For example, in the 100\% southeastern residence duration category, prevalence of reduced kidney function was $12.2 \%$ and $11.3 \%$ in blacks and whites. Table 3 shows that duration of southeastern residence was not associated with odds of reduced kidney function among whites. Similarly, among blacks, we found no dose-response pattern. Additionally, tests for interactions of race with southeastern residence duration were not statistically significant.

Sensitivity analyses showed a similar lack of association of southeastern residence with reduced kidney function was seen when the stricter cutoff of eGFR $<45$ $\mathrm{ml} / \mathrm{min} / 1.73 \mathrm{~m}^{2}$ was used (data not shown). Incomestratified analyses (Table 4) showed that the associations of reduced kidney function with southeastern residence duration were similarly null in high- and low-income groups, with the exception of the more than half vs. none southeastern residence category in blacks of high income. With evenly spaced cutoffs (intervals of 20\%, excluding the $0 \%$ and $100 \%$ categories), results were similarly null, compared to those reported in the main analyses (data not shown). Also, whether participants had spent the first 18 years of life in the Southeast (vs. not) was not associated with reduced kidney function: $\mathrm{POR}=1.00$ (95\% CI, 0.89-1.12) and 0.96 (95\% CI, 0.84-1.09), for whites and blacks, respectively. Finally, the age $\times$ duration term was not statistically significant for whites $(P=0.90)$ or blacks $(P=0.86)$.

\section{Incidence of ESRD by southeastern residence duration}

Among whites, the crude incidence of ESRD was lowest in the all lifetime southeastern residence duration category and highest in the none category (536.1 and 1149.5 per million patient-years, respectively; Table 2). However, this difference was not statistically significant. In contrast, among blacks, those who had spent their entire life in the Southeast had the highest crude incidence of ESRD and those who had never lived in the region had the lowest incidence rate (4262.9 and 2829.2 per million patient-years, respectively; Table 2). Most categories of southeastern residence were not statistically significantly associated with ESRD incidence (Table 3). Blacks who lived their

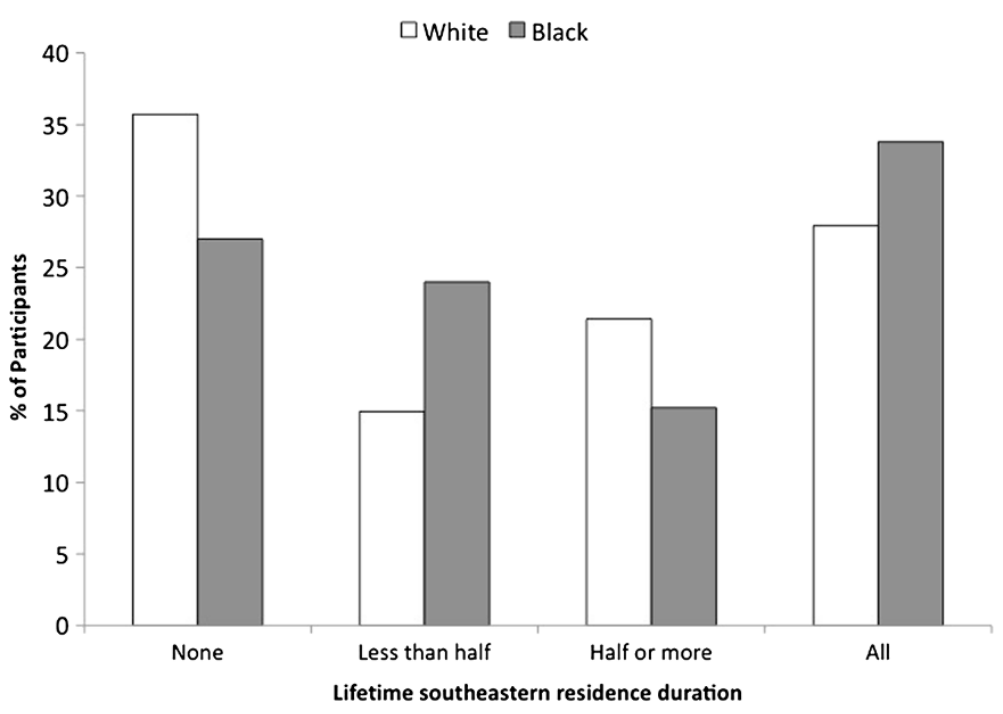

Figure 1 Crude distribution of lifetime southeastern residence duration, by race. Bars, crude percentage of participants in each category. Southeastern U.S. states included: North Carolina, South Carolina, Georgia, Alabama, Mississippi, Tennessee, Arkansas, and Louisiana; other included the 40 other contiguous U.S. states (excluding Alaska and Hawaii). 
entire lives in the Southeast had increased risk of ESRD relative to those who never lived in the Southeast (fully adjusted POR vs. none, 1.63; 95\% CI, 1.02-2.61). The statistical interaction of race with southeastern residence duration in this fully adjusted model was statistically significant $\left(P_{\text {interaction }}=0.011\right)$.

In sensitivity analyses, income-stratified analyses (Table 4) showed that the associations of ESRD with southeastern residence duration were similarly nonstatistically significant in high- and low-income groups. Associations were similar in the two income groups among whites. Among blacks, HRs were suggestive of a harmful effect of greater southeastern residence duration in those with low income but a protective effect in those with high income. The three-way interaction term of income, race, and southeastern residence duration was statistically significant $(P=0.028)$. When residence duration was categorized in evenly spaced intervals of length $20 \%$ (excluding the $0 \%$ and $100 \%$ categories), results were similar: only the $100 \%$ residence category was associated with greater risk of ESRD among blacks, with a HR of 1.63 (95\% CI, 1.02-2.61). The first 18 years spent in the Southeast (vs. not) was protective in whites $(\mathrm{HR}=0.66$, 95\% CI, 0.35-1.26) and harmful in blacks $(\mathrm{HR}=1.24$, 95\% CI, 0.86-1.79), but neither association was statistically significant. Finally, the age $\times$ duration term was statistically significant among whites $(P=0.02)$ but not blacks $(P=0.37)$. The significance of the interaction term appeared to be due to a lack of events in the $<50 \%$ duration category among younger whites and not due to any overall difference between older and younger whites in the association of duration with risk of incident ESRD, as the HRs for $100 \%$ vs. $0 \%$ categories were quite similar among whites $<65$ and $\geq 65$ years old: 0.50 (95\% CI, $0.14,1.81)$ and 0.44 ( $95 \%$ CI, $0.14,1.35)$, respectively.

\section{Discussion}

In this national cohort, we found that higher prevalence of albuminuria and reduced kidney function was not associated with longer duration of Southeastern residence among either whites or blacks. Results were suggestive of an association between lifetime southeastern residence duration and increased risk of ESRD, but only among blacks. The interaction between race and southeastern residence duration for ESRD suggests effect modification by race, such that lifetime exposure to the Southeast appeared to be harmful for blacks but not whites. This effect modification persisted among those with lower but not higher income.

Diabetes and hypertension account for the majority of ESRD in the United States [2]. Studies of diabetes have shown that it is more common among those living in the Southeast, often referred to as the "stroke belt" [3]. In fact, a "diabetes belt" [4] that overlays the stroke belt has recently been proposed, based upon national survey prevalence estimates. Hypertension has also been associated with the duration of residence in the stroke belt in a doseresponse manner (i.e., higher lifetime exposure to the stroke belt was associated with higher prevalence of hypertension) [5]. In addition, racial disparities in both diabetes and hypertension persist, with blacks having higher prevalence of both conditions compared to whites

Table 2 Crude prevalence of albuminuria and reduced kidney function and crude incidence of end-stage renal disease, by race and southeastern residence duration categories

\begin{tabular}{|c|c|c|c|c|c|c|c|c|c|c|}
\hline \multirow[t]{3}{*}{ Outcome } & \multicolumn{10}{|c|}{ Lifetime southeastern residence duration } \\
\hline & \multicolumn{5}{|c|}{ White } & \multicolumn{5}{|c|}{ Black } \\
\hline & None & $<$ Half & $\geq$ Half & All & $\mathbf{P}$ & None & $<$ Half & $\geq$ Half & All & $\mathbf{P}$ \\
\hline \multicolumn{11}{|l|}{ Crude prevalence of albuminuria } \\
\hline No. of events & 670 & 245 & 399 & 560 & $0.044^{a}$ & 534 & 443 & 243 & 671 & $0.037^{\mathrm{a}}$ \\
\hline No. of individuals & 5619 & 2348 & 3377 & 4380 & $0.149^{b}$ & 2728 & 2431 & 1541 & 3373 & $0.876^{b}$ \\
\hline Prevalence (\%) & 11.9 & 10.4 & 11.8 & 12.8 & & 19.6 & 18.2 & 15.8 & 19.9 & \\
\hline \multicolumn{11}{|c|}{ Crude prevalence of reduced kidney function } \\
\hline No. of events & 619 & 218 & 347 & 497 & $0.042^{\mathrm{a}}$ & 316 & 301 & 152 & 417 & $0.067^{\mathrm{a}}$ \\
\hline No. of individuals & 5640 & 2364 & 3414 & 4418 & $0.670^{\mathrm{b}}$ & 2714 & 2443 & 1552 & 3420 & $0.895^{b}$ \\
\hline Prevalence (\%) & 11.0 & 9.2 & 10.2 & 11.3 & & 11.6 & 12.3 & 9.8 & 12.2 & \\
\hline \multicolumn{11}{|c|}{ Crude incidence of end-stage renal disease } \\
\hline No. of events & 23 & 5 & 12 & 8 & $0.278^{a}$ & 30 & 29 & 15 & 48 & $0.076^{a}$ \\
\hline No. of individuals & 5839 & 2447 & 3504 & 4564 & $0.192^{b}$ & 2866 & 2537 & 1618 & 3575 & $0.009^{b}$ \\
\hline Incidence (per million person-years) & 1149.5 & 589.8 & 1007.6 & 536.1 & & 2829.2 & 3152.7 & 2891.9 & 4262.9 & \\
\hline
\end{tabular}

Southeastern U.S. states included: North Carolina, South Carolina, Georgia, Alabama, Mississippi, Tennessee, Arkansas, and Louisiana; other included the 40 other contiguous U.S. states (excluding Alaska and Hawaii).

${ }^{\mathrm{a}} \mathrm{By} X^{2}$ (albuminuria, reduced kidney function) and log-rank (end-stage renal disease) tests of equality across southeastern exposure categories.

${ }^{b}$ By Cochran-Armitage (albuminuria, reduced kidney function) and log-rank (end-stage renal disease) tests for trend across southeastern exposure categories. 
Table 3 Crude and adjusted prevalence odds ratios for albuminuria and reduced kidney function and hazard ratios for incident ESRD, by race and southeastern residence duration categories

\begin{tabular}{|c|c|c|c|c|c|c|c|c|c|}
\hline \multirow[t]{3}{*}{ Model } & \multicolumn{8}{|c|}{ Lifetime southeastern exposure } & \multirow[t]{3}{*}{$P^{a}$} \\
\hline & \multicolumn{4}{|c|}{ White } & \multicolumn{4}{|c|}{ Black } & \\
\hline & None & $<$ Half & $\geq$ Half & All & None & $<$ Half & $\geq$ Half & All & \\
\hline \multicolumn{10}{|c|}{ Prevalence odds ratios $(95 \% \mathrm{Cl})$ for albuminuria } \\
\hline Unadjusted & Ref. & $0.86(0.74-1.01)$ & $0.99(0.87-1.13)$ & $1.08(0.96-1.22)$ & Ref. & $0.92(0.80-1.05)$ & $0.77(0.65-0.91)$ & $1.02(0.90-1.16)$ & 0.054 \\
\hline \multicolumn{10}{|l|}{ Adjusted $^{\mathrm{b}}$} \\
\hline + demographics & Ref. & $0.87(0.75-1.02)$ & $1.04(0.91-1.18)$ & $1.16(1.02-1.31)$ & Ref. & $0.87(0.76-1.00)$ & $0.80(0.68-0.95)$ & $1.08(0.95-1.22)$ & $<0.001$ \\
\hline+ SES & Ref. & $0.89(0.76-1.04)$ & $1.02(0.89-1.17)$ & $1.08(0.96-1.23)$ & Ref. & $0.84(0.73-0.97)$ & $0.78(0.66-0.92)$ & $0.99(0.86-1.13)$ & 0.178 \\
\hline+ clinical & Ref. & $0.86(0.73-1.01)$ & $0.94(0.82-1.08)$ & $1.00(0.88-1.14)$ & Ref. & $0.86(0.74-1.00)$ & $0.74(0.62-0.89)$ & $0.92(0.80-1.05)$ & 0.265 \\
\hline \multicolumn{10}{|c|}{ Prevalence odds ratios $(95 \% \mathrm{Cl}$ ) for reduced kidney function } \\
\hline Unadjusted & Ref. & $0.82(0.70-0.97)$ & $0.92(0.80-1.05)$ & $1.03(0.91-1.17)$ & Ref. & $1.07(0.90-1.26)$ & $0.82(0.67-1.01)$ & $1.05(0.90-1.23)$ & 0.051 \\
\hline \multicolumn{10}{|l|}{ Adjusted $^{b}$} \\
\hline + demographics & Ref. & $0.97(0.81-1.15)$ & $0.98(0.80-1.22)$ & $1.19(1.03-1.40)$ & Ref. & $0.89(0.75-1.05)$ & $1.00(0.87-1.16)$ & $1.13(0.99-1.30)$ & 0.843 \\
\hline+ SES & Ref. & $0.94(0.79-1.13)$ & $0.96(0.77-1.18)$ & $1.11(0.94-1.31)$ & Ref. & $0.91(0.76-1.08)$ & $0.99(0.86-1.05)$ & $1.08(0.94-1.23)$ & 0.937 \\
\hline+ clinical & Ref. & $0.96(0.81-1.15)$ & $0.92(0.74-1.14)$ & $1.06(0.80-1.26)$ & Ref. & $0.88(0.74-1.35)$ & $0.93(0.80-1.08)$ & $1.00(0.87-1.15)$ & 0.878 \\
\hline \multicolumn{10}{|c|}{ Hazard ratios $(95 \% \mathrm{Cl})$ for incident end-stage renal disease } \\
\hline Unadjusted & Ref. & $0.51(0.19-1.34)$ & $0.91(0.45-1.84)$ & $0.53(0.24-1.18)$ & Ref. & $1.16(0.70-1.93)$ & $1.11(0.60-1.06)$ & $1.73(1.10-2.74)$ & 0.014 \\
\hline \multicolumn{10}{|l|}{ Adjusted $^{b}$} \\
\hline + demographics & Ref. & $0.52(0.20-1.36)$ & $0.94(0.47-1.89)$ & $0.55(0.25-1.24)$ & Ref. & $1.16(0.69-1.93)$ & $1.11(0.60-2.07)$ & $1.74(1.10-2.75)$ & 0.013 \\
\hline+ SES & Ref. & $0.54(0.21-1.44)$ & $0.93(0.46-1.88)$ & $0.51(0.23-1.14)$ & Ref. & $1.17(0.70-1.96)$ & $1.09(0.59-2.04)$ & $1.66(1.04-2.66)$ & 0.013 \\
\hline + clinical & Ref. & $0.51(0.19-1.36)$ & $0.91(0.45-1.84)$ & $0.50(0.22-1.14)$ & Ref. & $1.23(0.74-2.06)$ & $1.02(0.54-1.93)$ & $1.63(1.02-2.61)$ & 0.011 \\
\hline
\end{tabular}

Southeastern U.S. states included: North Carolina, South Carolina, Georgia, Alabama, Mississippi, Tennessee, Arkansas, and Louisiana; other included the 40 other contiguous U.S. states (excluding Alaska and Hawaii). ${ }^{a} P$ for interaction by Wald $x^{2}$ test between race and overall percentage of lifetime lived in the southeastern United States.

${ }^{b}$ Demographics: age, gender, race (overall models only); SES: education, income clinical; diabetes, hypertension (by self-reported medications or glucose/BP). 
Table 4 Adjusted $^{a}$ prevalence odds ratios for albuminuria and reduced kidney function and hazard ratios for incident ESRD, by income, race, and southeastern residence duration

\begin{tabular}{|c|c|c|c|c|c|c|c|c|c|c|}
\hline \multirow[t]{3}{*}{ Income stratum } & \multicolumn{8}{|c|}{ Lifetime southeastern residence duration } & \multirow[t]{3}{*}{$P_{\text {raceXduration }}^{\mathrm{b}}$} & \multirow[t]{3}{*}{$\overline{P_{\text {incomeXraceXduration }}^{\complement}}$} \\
\hline & \multicolumn{4}{|c|}{ White } & \multicolumn{4}{|c|}{ Black } & & \\
\hline & None & $<$ Half & $\geq$ Half & All & None & $<$ Half & $\geq$ Half & All & & \\
\hline \multicolumn{11}{|c|}{ Prevalence odds ratios $(95 \% \mathrm{Cl})$ for albuminuria } \\
\hline Income $<\$ 35,000$ & Ref. & $0.97(0.74-1.26)$ & $0.99(0.80-1.23)$ & $1.01(0.83-1.26)$ & Ref. & $0.85(0.70-1.04)$ & $0.75(0.60-0.95)$ & $0.94(0.78-1.12)$ & 0.415 & 0.538 \\
\hline Income $\geq \$ 35,000$ & Ref. & $0.86(0.68-1.07)$ & $0.89(0.72-1.09)$ & $1.02(0.84-1.23)$ & Ref. & $0.86(0.66-1.11)$ & $0.71(0.52-0.98)$ & $0.98(0.76-1.26)$ & 0.859 & \\
\hline \multicolumn{11}{|c|}{ Prevalence odds ratios $(95 \% \mathrm{Cl})$ for reduced kidney function } \\
\hline Income $<\$ 35,000$ & Ref. & $0.86(0.65-1.14)$ & $0.94(0.75-1.18)$ & $1.06(0.87-1.29)$ & Ref. & $0.97(0.77-1.22)$ & $1.00(0.76-1.32)$ & $1.02(0.82-1.27)$ & 0.838 & 0.053 \\
\hline Income $\geq \$ 35,000$ & Ref. & $0.79(0.61-1.01)$ & $0.89(0.71-1.11)$ & $0.82(0.66-1.03)$ & Ref. & $0.99(0.71-1.39)$ & $0.59(0.37-0.94)$ & $1.17(0.83-1.64)$ & 0.034 & \\
\hline \multicolumn{11}{|c|}{ Hazard ratios $(95 \% \mathrm{Cl})$ for incident end-stage renal disease } \\
\hline Income $<\$ 35,000$ & Ref. & $0.50(0.11-2.28)$ & $1.16(0.47-2.89)$ & $0.43(0.14-1.38)$ & Ref. & $1.57(0.81-3.04)$ & $1.51(0.70-3.28)$ & $1.98(1.08-3.64)$ & 0.069 & 0.028 \\
\hline Income $\geq \$ 35,000$ & Ref. & $0.66(0.18-2.46)$ & $0.56(0.15-2.07)$ & $0.79(0.24-2.56)$ & Ref. & $0.82(0.32-2.10)$ & $0.20(0.03-1.53)$ & $0.56(0.17-1.82)$ & 0.797 & \\
\hline
\end{tabular}


in the United States [7]. Given these established associations of diabetes and hypertension-strong risk factors for development and progression of CKD-with the U.S. southeastern states and race, we expected that longer residence in this region would be associated with higher prevalence of CKD and incidence of ESRD, and that the associations might be even stronger in blacks compared to whites.

However, in this national population-based cohort, while we did observe increasing prevalence of diabetes and, to a lesser extent, hypertension with higher duration of residence in the Southeast, the same was not true for the prevalence of albuminuria and reduced kidney function, or for incident ESRD. Differential CKD progression may partially explain these results. Faster progression among blacks is postulated to be responsible for decreased prevalence of CKD but increased ESRD incidence reported among blacks as compared to whites [8]. Mortality also differs by race: blacks with CKD have higher mortality at every stage of CKD than comparable whites [9]. Thus, racial differences in CKD prevalence and CKD-related mortality do not seem to account for the differences in progression to ESRD $[9,10]$. However, higher early mortality and faster progression among blacks with CKD [11] may mean that this study, which recruited communitydwelling adults $\geq 45$ years of age, was less likely to capture blacks with earlier vs. advanced-stage CKD. Additionally, if those with rapidly progressing CKD are more or less sensitive to geographic risk factors than those with slowly progressing CKD and were less likely to be captured in our study, our results may be under- or over-estimating the effect of southeastern residence duration on CKD, particularly among blacks.

Other important factors may partially account for our observed results. For example, higher income could offset deleterious effects of regional exposure in many ways, including: increasing quality of medical care received; facilitating higher adherence to healthier lifestyles and prescribed medical therapies; and improving residential neighborhood, in terms of crime, education, or pollution. Indeed, CKD has been shown to be more common in those with lower income, particularly among blacks [12-14]. Here, we found that the potential effect modifications by race for ESRD incidence were strongest in those with lower income. Those with lower income may have fewer opportunities to move for better educational and job opportunities, which in turn may affect their risk for incidence and progression of kidney disease.

Also, lifetime exposure (or cumulative life course exposure) to the southeastern United States may not be as important as other geographic factors, including early regional exposure (or critical period exposure). In fact, Howard et al. [5] reported that early stroke belt exposure (place of birth, in childhood and/or adolescence) was more strongly associated with hypertension in REGARDS, compared to other periods. The authors found that early stroke belt exposure was a strong risk factor, particularly among black participants; whereas lifetime exposure was more strongly associated with hypertension in white participants. Similarly, southeastern U.S. place of birth and adult residence were both shown to be independently associated with stroke mortality, although childhood exposure was not available in this study [15]. However, we found no association between southeastern residence during the first 18 years of life and prevalence of albuminuria or reduced kidney function. And, while protective and harmful effects were suggested for ESRD among whites and blacks, respectively, these results were neither statistically significant nor substantially different (in either race) from those obtained in our main analyses of lifetime exposure.

Residential mobility may also play a role. In general, higher residential mobility is thought to be associated with poorer health $[16,17]$ and there is some evidence of an association between higher mobility and higher prevalence of hypertension [18]. However, it has been suggested that such an effect is highly dependent on age and health status at the time of migration [19]. Our results among blacks suggest that increased residential mobility, at least in and out of the Southeast, may be partially protective against albuminuria, although the reverse effect (declining health leading to decreased mobility) cannot be entirely ruled out since the duration of albuminuria is unknown. Whether this can be explained by the reasons for moving-e.g., educational or occupational opportunities-or by explanations such as the "healthy migrant" effect or "salmon bias," which are often invoked to explain superior health status of immigrant populations $[19,20]$, requires further research.

While these results demonstrate geographical variation specifically within the United States, they are likely to be relevant to international populations as well. For example, in Japan, another highly industrialized country, incidence rates of ESRD were shown to be higher in the northern vs. southern regions, mirroring known regional patterns of hypertension and stroke, despite a relatively racially homogenous population compared to the United States [21]. However, recent studies show that the geographic differences in ESRD incidence have all but disappeared in the last decade in Japan [22], suggesting that interventions may be effective in reducing geographic disparities. In India, the identification of such existing geographic variations, as was seen with the national Indian CKD registry data, particularly with respect to the prevalence of hypertensive CKD [23], is critical to development and implementation of interventions that could reduce or eliminate disparities, as has occurred in Japan. Population genetic studies could help identify 
global subgroups, such as those of sub-Saharan African ancestry, who may be at higher risk [24]. Such populations could be targeted for early interventions that could prevent the development of geographic disparities as these populations transition to having chronic disease as the main population health concern [25].

In addition to the limitations discussed above, there are other limitations worthy of mention. First, residence was self-reported and recall of all relocations to exact year may be somewhat flawed. Also, this exposure reflects duration of residence in the Southeast but not necessarily the amount of exposure to cultural, lifestyle, and/or environmental factors of the region, which may account for increased risk of disease, including CKD. Cohort effects could also an issue, although interactions between age and duration of southeastern residence were generally non-statistically significant, except in the models of ESRD in whites. Both albuminuria and reduced kidney function are based upon single measurements and some misclassification of CKD is likely. Without good measures of diabetes and hypertension control over time, we cannot ascertain whether these differ geographically and what effect these might have on CKD prevalence and ESRD incidence by region. Additionally, unmeasured genetic and environmental factors cannot be examined to determine the contributions of each to observed differences. ESRD is rare, leading to small numbers of events and possibly unstable estimates in southeastern exposure categories, particularly for income-stratified models. As with all observational studies, causal inference is limited. However, this study also has several strengths, including a large study sample size with adequate follow-up, ascertainment of ESRD through active follow-up, and a sampling scheme that provided adequate numbers of participants in both race and Southeastern residence.

\section{Conclusions}

We found three unexpected findings in our analysis of kidney disease and duration of residence in the Southeast. First, we found no association of southeastern residence duration with either albuminuria or reduced kidney function, regardless of race. Second, lifetime southeastern residence duration was associated with increased risk of ESRD in blacks only, and we found no evidence of a dose-response association with increasing southeastern residence duration. Finally, blacks (but not whites) with partial southeastern residence duration were possibly less likely to have albuminuria than those who lived their entire lives either within or outside of the Southeast. Residential history data are not commonly collected in cohort studies. However, these unexpected results regarding the effects of geography, and particularly residence in the Southeast, on the prevalence and incidence of kidney disease among blacks and whites may provide a motivation for the collection and examination of more granular geographic data, including both location and mobility, in prospective cohort studies around the world.

\section{Methods}

\section{Study design and population}

The REGARDS study is a national population-based cohort study that recruited 30,239 community-dwelling participants aged $\geq 45$ years, of whom $55 \%$ were women, $42 \%$ were black, and 58\% were white. Enrollment of the cohort occurred between 2003 and 2007. Approximately 56\% of the cohort was recruited from the southeastern states, and the remaining $44 \%$ resided in the other 40 contiguous states. Exclusion criteria were race/ethnicity other than non-Hispanic African-American (black) or white, malignancy or other medical conditions that prevented longterm participation in the study, cognitive impairment, nursing home residence, or non-English spoken language. Consent was obtained verbally and later in writing. The study was approved and monitored by institutional review boards at all participating institutions.

\section{Data collection}

Detailed study methods have been published previously [26]. Briefly, individuals were identified from commercially available lists of residents, and recruited using an initial mailing followed by telephone contact. Using a computer-assisted telephone interview, trained interviewers obtained demographic information and medical history. A brief physical exam including blood pressure measurements and collection of blood and urine samples was conducted in-person (usually in the home) 3-4 weeks after the telephone interview. A review of medication pill bottles was conducted as well. Self-administered questionnaires were left with the participant to be completed after the in-person visit and returned by selfaddressed prepaid envelopes. Follow-up interviews are attempted every 6 months, and there is a standard protocol for tracking missed contacts.

\section{Southeastern residence duration}

Duration of residence in the southeastern United States (North Carolina, South Carolina, Georgia, Alabama, Mississippi, Tennessee, Arkansas, and Louisiana) was determined at baseline by a self-administered study residential history questionnaire ("Places You Have Lived Questionnaire"), on which participants report the location (city/state) of all places where they had lived for at least 1 year, from birth to study enrollment, and their ages at each move. Southeastern residence duration was defined as (time lived in the Southeast)/(time lived in the United States)*100. Years lived out of the country, or 
in unknown locations, were not included (affecting $n=4725$ participants, median of 5.5 years excluded). Details of the process for matching reported cities with U.S. Census data to minimize misspecification due to misspellings or other mistakes have been published previously [5]. Briefly, participant reports of city/state were matched with U.S. Census Bureau files; in the event of a mismatch, the 10 mnemonically closest city/state combinations were reviewed and evaluated as to the strength of the match by study staff, and those participants with addresses that lacked a strong match at the end of the review process were removed. For analyses, southeastern residence duration was categorized as none $(0 \%)$, less than half $(>0$ and $<50 \%)$, half or more $(\geq 50 \%$ and $<100 \%)$, and all $(100 \%)$ of the participant's life, to allow for assessment of dose-response trends and to maintain statistical power without subgroups.

\section{Albuminuria}

Urine albumin and creatinine were measured using a BN ProSpec Nephelometer (Dade Behring, Marburg, Germany; interassay coefficient of variation, $2.2-4.3 \%$ ) and Modular-P chemistry analyzer (Roche Hitachi, Indianapolis, IN; interassay coefficient of variation, 2.6-8.6\%), respectively [27]. Albuminuria was defined as a baseline urinary albumin:creatine ratio (ACR) $\geq$ $30 \mathrm{mg} / \mathrm{g}$.

\section{Reduced kidney function}

Serum creatinine was measured by colorimetric reflectance spectrophotometry using the Ortho Vitros Clinical Chemistry System 950IRC instrument (Johnson \& Johnson Clinical Diagnostics, New Brunswick, NJ). eGFR was calculated from isotope dilution mass spectrometrytraceable serum creatinine values using the CKD-EPI equation [28]. Reduced kidney function was defined as a baseline estimated glomerular filtration rate (eGFR) $<60$ $\mathrm{ml} / \mathrm{min} / 1.73 \mathrm{~m}^{2}$, corresponding to stage 3-5 (moderatesevere) CKD [29]. Sensitivity analyses using a stricter cutoff of eGFR $<45 \mathrm{ml} / \mathrm{min} / 1.73 \mathrm{~m}^{2}$ (stages 3B-5), which are more likely to be consistently reduced on multiple measurement, were also conducted.

\section{ESRD}

The incidence of ESRD was determined by linked data from the United States Renal Data System registry, which records $>90 \%$ of incident ESRD in the United States. Follow-up time included time from study enrollment to first ESRD treatment, death, or last date of follow-up (9/1/09; mean follow-up, 3.4 years). Participants who initiated ESRD prior to enrollment were excluded from these analyses, and included participants were censored at death or last date of follow-up.

\section{Potential confounders}

Age, sex, race (white and black), income $(<\$ 20,000, \$ 20$ $34,999, \$ 35,000-74,999$, and $>\$ 75,000$ ), education (less than high school, high school graduate, some college, college graduate), insurance (yes/no), doctor/clinic for regular medical care (yes/no), self-reported use of oral hypoglycemics/insulin or anti-hypertensive medications (yes/no), current smoking (yes/no), immediate family history of ESRD (yes/no), and use of drugs (yes/no) known to affect CKD and its progression [non-steroidal anti-inflammatory drugs, angiotensin-converting enzyme inhibitors (ACEIs), and angiotensin receptor blockers (ARBs)] were all collected at baseline. Height, weight, and blood pressure were measured during the in-home exam. Blood pressure (average of two measurements) was measured per a standard protocol by a trained technician after the participant rested for 5 minutes, using an appropriately sized cuff and an aneroid sphygmomanometer (American Diagnostic Corporation, Hauppage, NY). Glucose was measured by colorimetric reflectance spectrophotometry using the Ortho Vitros Clinical Chemistry System 950IRC instrument (Johnson \& Johnson Clinical Diagnostics, New Brunswick, NJ). Body mass index (BMI) was calculated as weight (kg) divided by height $(\mathrm{m})$ squared. Diabetes was defined as selfreported use of oral hypoglycemics or insulin, fasting glucose $\geq 126 \mathrm{mg} / \mathrm{dl}$, or random glucose $\geq 200 \mathrm{mg} / \mathrm{dl}$. Hypertension was defined as self-reported use of antihypertensive medication, systolic blood pressure $\geq 140$ $\mathrm{mmHg}$ or diastolic blood pressure $\geq 90 \mathrm{mmHg}$.

\section{Statistical analyses}

Participant characteristics were compared across category of southeastern residence duration using $X^{2}$ or ANOVA tests for categorical and continuous variables, respectively. Crude prevalence of albuminuria and reduced kidney function and crude incidence of ESRD were calculated by residence category and race. Racestratified logistic models were used to determine the adjusted associations [prevalence odds ratios (PORs)] between southeastern residence duration and the prevalence of albuminuria and reduced kidney function. Racestratified Cox proportional hazards models of time to ESRD were used to obtain hazard ratios (HRs) of incident ESRD by race and southeastern residence duration. Groups of covariates were entered sequentially to the models to assess confounding: demographics (age, sex), then socioeconomic status (SES; income, education), and finally clinical (diabetes, hypertension). Sensitivity analyses were performed in which reduced kidney function was defined by eGFR $<45 \mathrm{ml} / \mathrm{min} / 1.73 \mathrm{~m}^{2}$. Further sensitivity analyses using evenly spaced (at 20\% increments, excluding $0 \%$ and 100\%) cutoffs and using a dichotomous variable assessing early-life southeastern residence 
(first 18 years spent in the Southeast, yes vs. no) were also performed. Finally, potential effect modification by income (with higher income potentially protecting individuals from any negative regional environmental effect) was assessed via examination of the association within low- and high-income groups $(<\$ 35,000$ and $>\$ 35,000$ annual income, respectively). Potential effect modification by age, which might indicate a cohort effect, wherein effects may be weaker in those born later (due to society-level changes over time), was also assessed. The statistical significance of interaction terms was assessed with Wald $\chi^{2}$ tests. For this study, participants were limited to those with lifetime residence information $(N=27,070)$; of these participants, those with complete information for assessment of prevalent albuminuria $(N=25,797)$ and reduced kidney function $(N=25,965)$ and free of ESRD at the start of the study $(N=26,950)$ were included in respective analyses. All analyses were performed using SAS v. 9.2 (SAS Institute, Cary, NC) and Stata v. 12 (StataCorp, College Station, TX).

\section{Competing interests}

The authors declare that they have no competing interests.

\section{Authors' contributions}

LP carried out the analysis and draft the manuscript; $\mathrm{VJH}$ participated in the design and coordination of the study and provided feedback on the written manuscript, SJ, PM, DR, DTL, and DGW provided feedback on the analyses and drafts of the manuscript; GH served as principal investigator of the REGARDS study and provided feedback on drafts of the manuscript; and WMM served as primary mentor to LP and helped to design and perform the analyses and draft the manuscript. All authors read and approved the final manuscript.

\section{Acknowledgements}

We thank the participants and staff of the REGARDS study. This research project is supported by a cooperative agreement U01 NS041588 from the National Institute of Neurological Disorders and Stroke, National Institutes of Health, Department of Health and Human Services. The content is solely the responsibility of the authors and does not necessarily represent the official views of the National Institute of Neurological Disorders and Stroke or the National Institutes of Health. Representatives of the funding agency have been involved in the review of the manuscript but not directly involved in the collection, management, analysis or interpretation of the data. The authors thank the other investigators, the staff, and the participants of the REGARDS study for their valuable contributions. A full list of participating REGARDS investigators and institutions can be found at http://www. regardsstudy.org. Additional funding was provided by an investigatorinitiated grant-in-aid from Amgen Inc. to Dr. Warnock.

\section{Author details \\ 'Department of Epidemiology, Rollins School of Public Health, Emory University School of Medicine, Emory University, Atlanta, GA, USA. ${ }^{2}$ Laney Graduate School, Emory University School of Medicine, Emory University, Atlanta, GA, USA. ${ }^{3}$ Department of Epidemiology, University of Alabama at Birmingham, Birmingham, AL, USA. ${ }^{4}$ Department of Biostatistics, School of Public Health, University of Alabama at Birmingham, Birmingham, AL, USA. ${ }^{5}$ Division of Nephrology, School of Medicine, University of Alabama at Birmingham, Birmingham, AL, USA. ${ }^{6}$ Department of Medicine, Medical University of South Carolina, Charleston, SC, USA. 'Division of Nephrology, Emory University School of Medicine, Emory University, Atlanta, GA, USA.}

Received: 3 January 2013 Accepted: 3 March 2013

Published: 21 March 2013

\section{References}

1. Coresh J, Selvin E, Stevens LA, Manzi J, Kusek JW, Eggers P, Van Lente F, Levey AS: Prevalence of chronic kidney disease in the United States. JAMA 2007, 298(17):2038-2047.

2. U.S. Renal Data System: USRDS 2011 Annual Data Report: Atlas of Chronic Kidney Disease and End-Stage Renal Disease in the United States. Bethesda MD: National Institutes of Health, National Institute of Diabetes and Digestive and Kidney Diseases; 2011.

3. Voeks JH, McClure LA, Go RC, Prineas RJ, Cushman M, Kissela BM, Roseman $J M$ : Regional differences in diabetes as a possible contributor to the geographic disparity in stroke mortality: the REasons for Geographic And Racial Differences in Stroke Study. Stroke 2008, 39(6):1675-1680.

4. Barker LE, Kirtland KA, Gregg EW, Geiss LS, Thompson TJ: Geographic distribution of diagnosed diabetes in the U.S.: a diabetes belt. Am J Prev Med 2011, 40(4):434-439.

5. Howard VJ, Woolson RF, Egan BM, Nicholas JS, Adams RJ, Howard G, Lackland DT: Prevalence of hypertension by duration and age at exposure to the stroke belt. J Am Soc Hypertens 2010, 4(1):32-41.

6. McClellan AC, Plantinga L, McClellan WM: Epidemiology, geography and chronic kidney disease. Curr Opin Nephrol Hypertens 2012, 21:323-328.

7. Fryar CD, Hirsch R, Eberhardt MS, Yoon SS, Wright JD: Hypertension, high serum total cholesterol, and diabetes: racial and ethnic prevalence differences in U.S. adults, 1999-2006. NCHS Data Brief 2010, 36:1-8.

8. Hsu CY, Lin F, Vittinghoff E, Shlipak MG: Racial differences in the progression from chronic renal insufficiency to end-stage renal disease in the United States. J Am Soc Nephrol 2003, 14(11):2902-2907.

9. Choi Al, Rodriguez RA, Bacchetti P, Bertenthal D, Hernandez GT, O'Hare AM: White/black racial differences in risk of end-stage renal disease and death. Am J Med 2009, 122(7):672-678.

10. Newsome BB, MCClellan WM, Allison JJ, Eggers PW, Chen SC, Collins AJ, Kiefe Cl, Coffey CS, Warnock DG: Racial differences in the competing risks of mortality and ESRD after acute myocardial infarction. Am J Kidney Dis 2008, 52(2):251-261.

11. Lopes AA, Port FK: Differences in the patterns of age-specific black/white comparisons between end-stage renal disease attributed and not attributed to diabetes. Am J Kidney Dis 1995, 25(5):714-721.

12. McClellan WM, Newsome BB, McClure LA, Howard G, Volkova N, Audhya P, Warnock DG: Poverty and racial disparities in kidney disease: the REGARDS study. Am J Nephrol 2010, 32(1):38-46.

13. Crews DC, Charles RF, Evans MK, Zonderman AB, Powe NR: Poverty, race, and $C K D$ in a racially and socioeconomically diverse urban population. Am J Kidney Dis 2010, 55(6):992-1000.

14. Hall YN, Choi Al, Chertow GM, Bindman AB: Chronic kidney disease in the urban poor. Clin J Am Soc Nephrol 2010, 5(5):828-835.

15. Glymour MM, Kosheleva A, Boden-Albala B: Birth and adult residence in the Stroke Belt independently predict stroke mortality. Neurology 2009, 73(22):1858-1865.

16. Lin KC, Huang HC, Bai YM, Kuo PC: Lifetime residential mobility history and self-rated health at midlife. J Epidemiol 2012, 22(2):113-122.

17. Bures RM: Childhood residential stability and health at midlife. Am J Public Health 2003, 93(7):1144-1148.

18. Metzner HL, Harburg E, Lamphiear DE: Residential mobility and urban-rural residence within life stages related to health risk and chronic disease in Tecumseh, Michigan. J Chronic Dis 1982, 35(5):359-374.

19. Findley SE: The directionality and age selectivity of the health-migration relation: evidence from sequences of disability and mobility in the United States. Int Migr Rev 1988, 22(3):4-29.

20. Abraido-Lanza AF, Dohrenwend BP, Ng-Mak DS, Turner JB: The Latino mortality paradox: a test of the "salmon bias" and healthy migrant hypotheses. Am J Public Health 1999, 89(10):1543-1548.

21. Usami T, Koyama K, Takeuchi O, Morozumi K, Kimura G: Regional variations in the incidence of end-stage renal failure in Japan. JAMA 2000, 284(20):2622-2624.

22. Wakamatsu-Yamanaka T, Fukuda M, Sato R, Naito T, Togawa H, Tomonari T, Kato Y, Miura T, Mizuno M, Ichikawa T, et al: Geographic differences in the increasing ESRD rate have disappeared in Japan. Clin Exp Nephrol 2011, 15(5):708-713.

23. Rajapurkar MM, John GT, Kirpalani AL, Abraham G, Agarwal SK, Almeida AF, Gang S, Gupta A, Modi G, Pahari D, et al: What do we know about chronic 
kidney disease in India: first report of the Indian CKD registry. BMC Nephrol 2012, 13:10.

24. Wasser WG, Tzur S, Wolday D, Adu D, Baumstein D, Rosset S, Skorecki K: Population genetics of chronic kidney disease: the evolving story of APOL1. J Nephrol 2012, 25(5):603-618.

25. Omran AR: The epidemiologic transition, A theory of the epidemiology of population change. Milbank Mem Fund Q 1971, 49(4):509-538.

26. Howard VJ, Cushman M, Pulley L, Gomez CR, Go RC, Prineas RJ, Graham A, Moy CS, Howard G: The reasons for geographic and racial differences in stroke study: objectives and design. Neuroepidemiology 2005, 25(3):135-143.

27. Warnock DG, Muntner P, McCullough PA, Zhang XA, McClure LA, Zakai N, Cushman M, Newsome BB, Kewalramani R, Steffes MW, et al: Kidney function, albuminuria, and all-cause mortality in the REGARDS (REasons for Geographic and Racial Differences in Stroke) study. Am J Kidney Dis 2010, 56(5):861-871.

28. Levey AS, Stevens LA, Schmid CH, Zhang YL, Castro AF 3rd, Feldman HI, Kusek JW, Eggers $P$, Van Lente $F$, Greene T, et al: A new equation to estimate glomerular filtration rate. Ann Intern Med 2009, 150(9):604-612.

29. Levey AS, Coresh J, Balk E, Kausz AT, Levin A, Steffes MW, Hogg RJ, Perrone RD, Lau J, Eknoyan G: National Kidney Foundation practice guidelines for chronic kidney disease: evaluation, classification, and stratification. Ann Intern Med 2003, 139(2):137-147.

doi:10.1186/1476-072X-12-17

Cite this article as: Plantinga et al: Association of duration of residence in the southeastern United States with chronic kidney disease may differ by race: the REasons for Geographic and Racial Differences in Stroke (REGARDS) cohort study. International Journal of Health Geographics 2013 12:17.

\section{Submit your next manuscript to BioMed Central and take full advantage of:}

- Convenient online submission

- Thorough peer review

- No space constraints or color figure charges

- Immediate publication on acceptance

- Inclusion in PubMed, CAS, Scopus and Google Scholar

- Research which is freely available for redistribution 